\title{
Effect of long non-coding RNA highly up-regulated in liver cancer (HULC) on the prognosis of cancer: a meta-analysis
}

\author{
Yong Li ${ }^{1, *}$, Yi-Hong Liu ${ }^{1,}{ }^{*}$, Xian Chen ${ }^{1}$, Yan-Juan Zhu ${ }^{1}$, Hai-Bo Zhang ${ }^{1}$, Yan Li ${ }^{1}$, Jian- \\ Ping Bai ${ }^{1}$, Li-Rong Liu ${ }^{1}$, Yan-Chun $\mathbf{Q} \mathbf{u}^{1}$ and Xin $\mathbf{Q} \mathbf{u}^{1}$ \\ ${ }^{1}$ Department of Oncology, Guangdong Provincial Hospital of Chinese Medicine, Guangzhou 510120, Guangdong, China \\ *Yong Li and Yi-Hong Liu contributed equally to this work \\ Correspondence to: Hai-Bo Zhang, email: bubu400865@sohu.com
}

Keywords: long non-coding RNAs, HULC, cancer, overall survival

Received: April 18, $2017 \quad$ Accepted: May 03, $2017 \quad$ Published: June 13, 2017

Copyright: Li et al. This is an open-access article distributed under the terms of the Creative Commons Attribution License 3.0 (CC BY 3.0), which permits unrestricted use, distribution, and reproduction in any medium, provided the original author and source are credited.

\section{ABSTRACT}

Some studies investigated the association between highly up-regulated in liver cancer (HULC) and the overall survival (OS) of cancer. However, the results were conflicted and inconclusive. Therefore, we performed this meta-analysis to determine the association between HULC and the OS of cancer. A comprehensive online search was conducted on Online electronic databases (PubMed, EMBASE, and Wanfang database) from the earliest date to Aug 30, 2016. The strength of the association was calculated with the HRs and respective $95 \%$ CIs. The expression of HULC was significantly associated with OS of cancers (HR $=2.12 ; 95 \%$ CI 1.61 - 2.79; $P<0.00001)$. In the subgroup analysis by ethnicity, the expression of HULC was significantly associated with OS in Chinese patients (HR $=2.04 ; 95 \%$ CI 1.55 - 2.70; $P<0.00001)$. In the subgroup analysis by cancer type, HULC was associated with OS in osteosarcoma patients (HR = 3.36; 95\% CI 1.02 - 11.07; $P=0.05)$ and in gastric cancer patients $(H R=2.17 ; 95 \% C I 1.08-4.38 ; P=0.03)$. We performed the sensitivity analysis to assess the stability of the meta-analysis. A significant association was found in studies with adjustment (HR $=2.01$; 95\% CI $1.35-2.99$; $P=0.0006$ ). In conclusion, this meta-analysis suggested that high expression of HULC was significantly associated with OS of cancer.

\section{INTRODUCTION}

Cancer is a disease, which come from interactions between genetic and environmental factors [1]. Although the target therapy and precision medicine have developed in some cancers, the outcome of most cancers is still poor and disappointing. Thus, it is urgent to find an useful biomarker of cancer prognosis.

long non-coding RNAs (lncRNAs) have important roles in biological processes. The role of lncRNAs is involved in many disease, including cancers [2]. For example, the expression of HOTAIR was a predictor of cancers [3].

Up-regulation of highly up-regulated in liver cancer (HULC) has been detected in many human malignancies [4]. Some studies investigated the association between
HULC and the survival of cancer [5-11]. However, the results were conflicted. Therefore, we did this metaanalysis to investigate the association between HULC and the survival of cancer.

\section{RESULTS}

Literature search

691 patients with cancer were included in this metaanalysis. All the studies were cohort studies. There were 6 studies of Asian populations and 1 study of American population. The cancer types included pancreatic cancer, osteosarcoma, hepatocellular carcinoma, gastric cancer, and diffuse large B-cell lymphoma. The sample sizes included from 33 to 304 . All the studies provided overall 
Table 1: Characteristics of the included studies

\begin{tabular}{|c|c|c|c|c|c|c|c|c|c|c|c|c|c|}
\hline $\begin{array}{l}\text { First } \\
\text { author }\end{array}$ & Year & $\begin{array}{l}\text { Study } \\
\text { design }\end{array}$ & $\begin{array}{c}\text { Study } \\
\text { location }\end{array}$ & Race & Cancer type & $\begin{array}{c}\text { Tumor } \\
\text { stage }\end{array}$ & $\begin{array}{l}\text { Samle } \\
\text { size }\end{array}$ & Outcome & $\begin{array}{l}\text { Cutoff } \\
\text { value }\end{array}$ & $\begin{array}{c}\text { Analytical } \\
\text { method }\end{array}$ & Covariants & $\begin{array}{l}\text { HR and } \\
95 \% \mathrm{CI}\end{array}$ & NOS \\
\hline Peng & 2014 & Cohort & China & Chinese & $\mathrm{PC}$ & NA & 304 & OS & NA & Multivariate & $\begin{array}{c}\text { Tumor size, } \\
\text { lymph node } \\
\text { metastasis, } \\
\text { vascular invasion }\end{array}$ & $\begin{array}{c}2.84(1.33- \\
6.06)\end{array}$ & 8 \\
\hline Sun & 2015 & Cohort & China & Chinese & Osteosarcoma & II-III & 78 & OS & Median & Multivariate & $\begin{array}{c}\text { Age, gender, } \\
\text { tumor size, } \\
\text { location, clinical } \\
\text { stage, metastasis }\end{array}$ & $\begin{array}{c}2.28(1.48- \\
3.51)\end{array}$ & 8 \\
\hline $\mathrm{Li}$ & 2016 & Cohort & China & Chinese & $\mathrm{HCC}$ & I-IV & 38 & OS & $\begin{array}{c}\text { Fold } \\
\text { change }\end{array}$ & NA & No & $\begin{array}{c}2.22(0.55- \\
8.96)\end{array}$ & 7 \\
\hline Jin & 2016 & Cohort & China & Chinese & GC & I-IV & 54 & OS & $\begin{array}{c}\text { Fold } \\
\text { change }\end{array}$ & NA & No & $\begin{array}{c}2.14(0.77- \\
5.95)\end{array}$ & 7 \\
\hline Zhang & 2016 & Cohort & China & Chinese & GC & NA & 42 & OS & $\begin{array}{c}\text { Fold } \\
\text { change }\end{array}$ & NA & No & $\begin{array}{c}2.20(0.84- \\
5.76)\end{array}$ & 7 \\
\hline Uzan & 2016 & Cohort & Brazil & American & Osteosarcoma & NA & 33 & OS & NA & Univariate & No & $\begin{array}{c}8.72(1.50- \\
50.70)\end{array}$ & 7 \\
\hline Peng & 2016 & Cohort & China & Chinese & DLBCL & I-IV & 142 & OS & NA & Multivariate & $\begin{array}{c}\text { B symptoms, } \\
\text { CHOP-like } \\
\text { treatment, } \\
\text { Rituximab, IPI, } \\
\text { Ann arbor stages }\end{array}$ & $\begin{array}{c}2.84(1.33- \\
6.06)\end{array}$ & 8 \\
\hline
\end{tabular}

PC, pancreatic cancer; HCC, hepatocellular carcinoma; GC, gastric cancer; DLBCL, diffuse large B-cell lymphoma; OS, overall survival; NOS, Newcastle-Ottawa Scale; NA, not available.

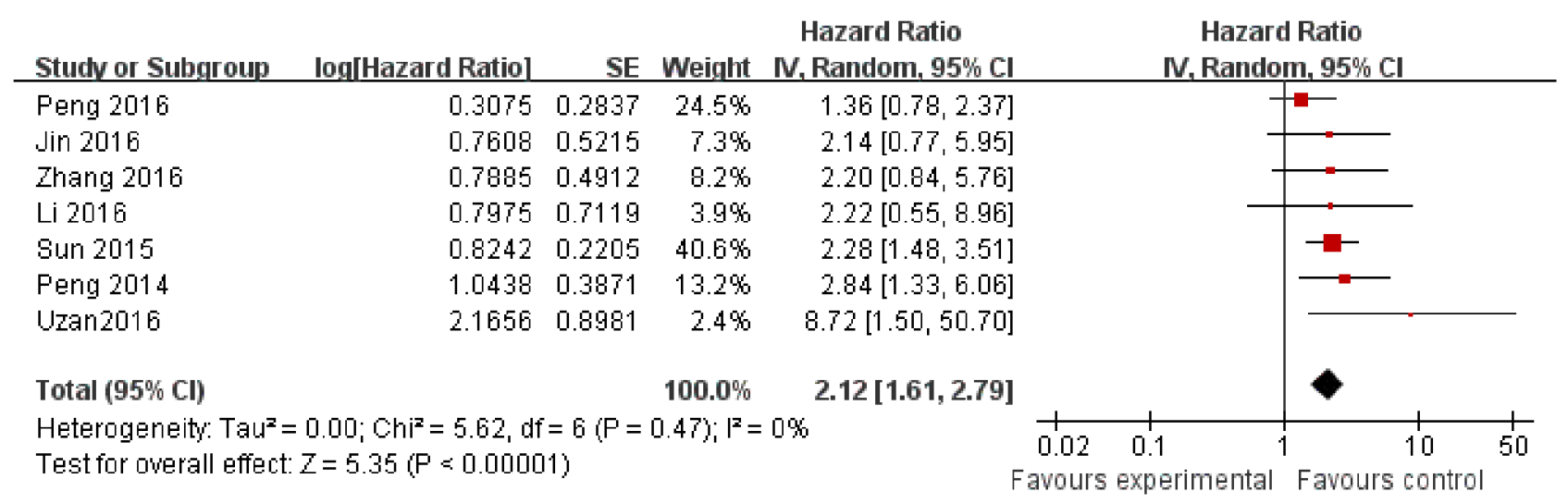

Figure 1: The association between HULC and OS in cancer.

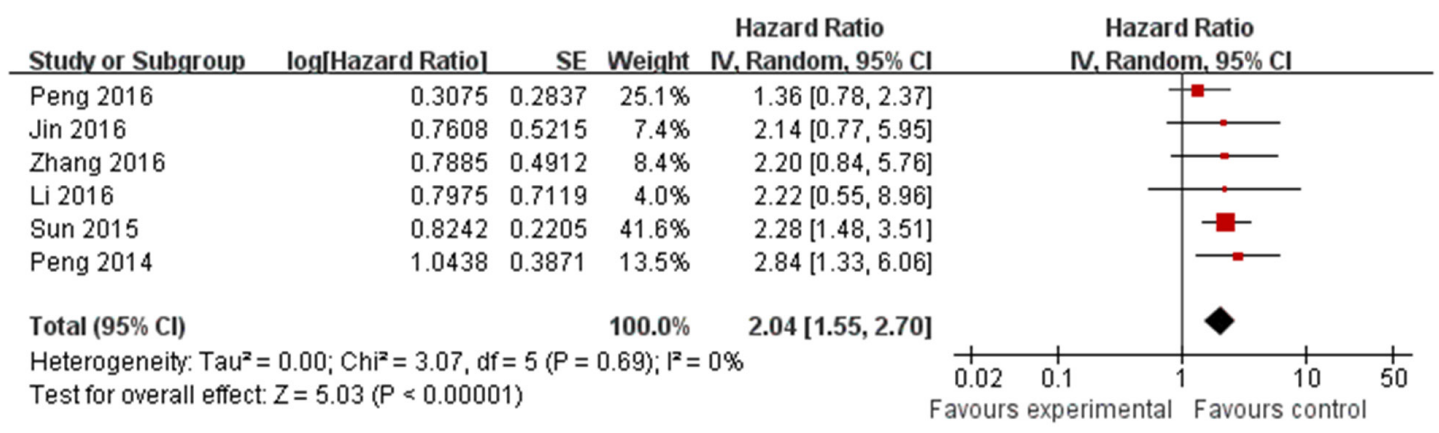

Figure 2: The association between HULC and OS in cancer in Chinese patients. 




Figure 3: The association between HULC and OS in osteosarcoma.

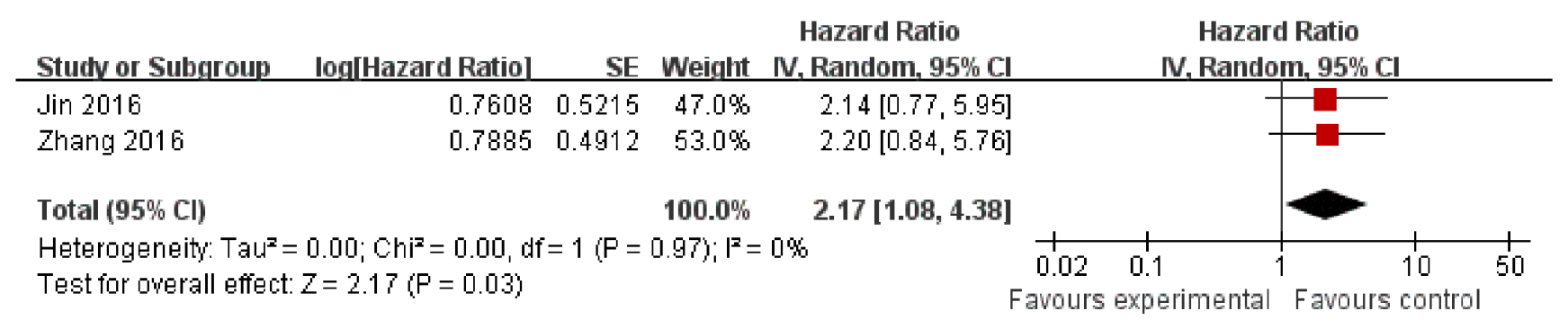

Figure 4: The association between HULC and OS in gastric cancer.

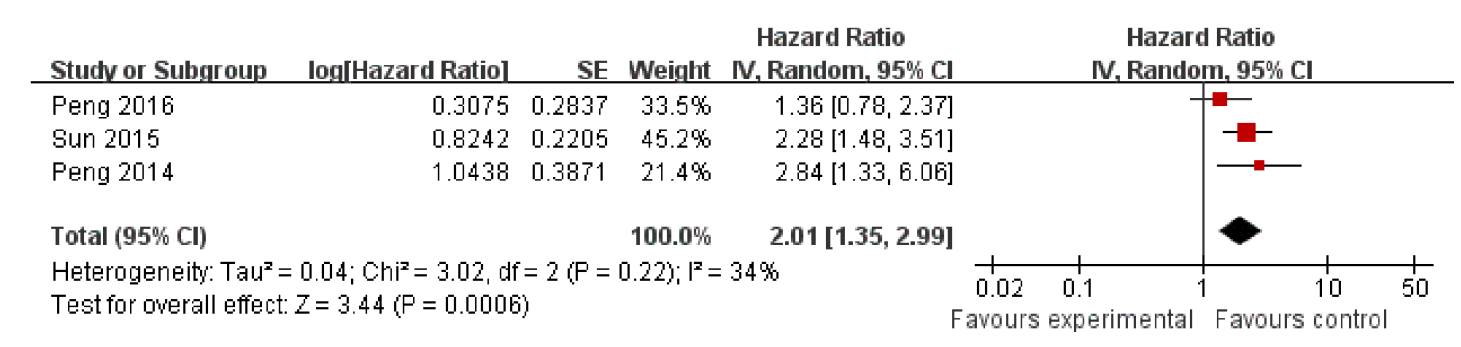

Figure 5: The adjusted result of the association between HULC and OS in cancer.

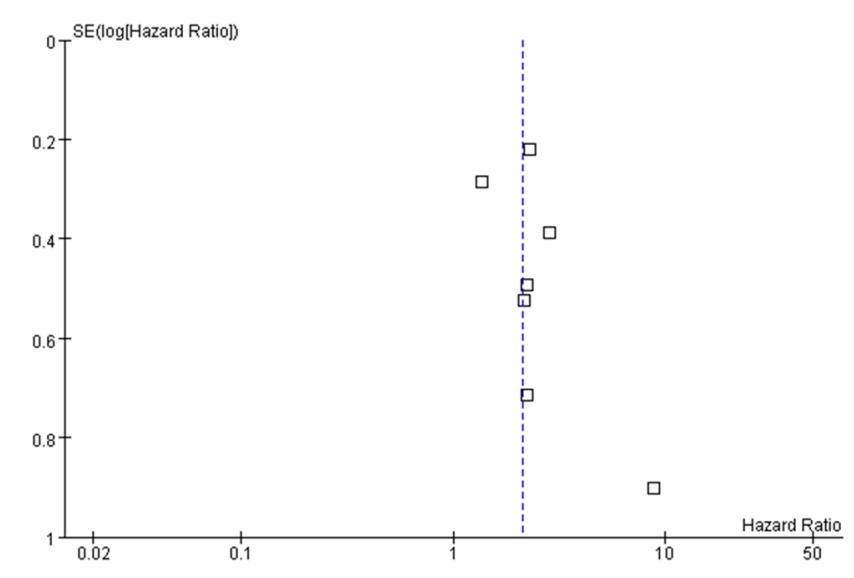

Figure 6: The funnel plot of the association between HULC and OS in cancer. 
survival (OS) data. The NOS were high, suggesting that the quality of the included studies were well. The characteristics of each study are presented in Table 1.

\section{Main result}

As shown in Figure 1, the expression of HULC was significantly associated with $\mathrm{OS}$ of cancers $(\mathrm{HR}=2.12$; 95\% CI $1.61-2.79 ; P<0.00001)$.

\section{Subgroup analysis by ethnicity}

In the subgroup analysis by ethnicity, the expression of HULC was significantly associated with OS in Chinese patients $(\mathrm{HR}=2.04 ; 95 \%$ CI $1.55-2.70 ; P<0.00001$; Figure 2).

\section{Subgroup analysis by cancer type}

In the subgroup analysis by cancer type, HULC was associated with $\mathrm{OS}$ in osteosarcoma patients $(\mathrm{HR}=3.36$; 95\% CI 1.02 - 11.07; $P=0.05$; Figure 3 ) and in gastric cancer patients $(\mathrm{HR}=2.17 ; 95 \% \mathrm{CI} 1.08-4.38 ; P=0.03$; Figure 4.

\section{Sensitivity analysis and publication bias analysis}

The sensitivity analysis was assessed to see the stability of the meta-analysis. A significant association was found in studies with adjustment $(\mathrm{HR}=2.01 ; 95 \% \mathrm{CI}$ $1.35-2.99 ; P=0.0006$; Figure 5).

The s funnel plot was symmetrical (Figure 6). In addition, no significant publication bias was detected by Begg's test $(P=0.272)$.

\section{DISCUSSION}

This meta-analysis with 691 cancer patients investigated the association between HULC and the survival of cancer. Results from this meta-analysis revealed that cancer patients with HULC might have shorter OS. Furthermore, Asians patients with HULC showed increased shorter OS in the subgroup analysis. Only one study using American patient included in this meta-analysis, thus more studies with other populations should be conducted to test this result. In the subgroup analysis by cancer type, we found a positive association in osteosarcoma patients and gastric cancer patients.

Wang et al. suggested HULC was an endogenous 'sponge'. The HULC down-regulates some microRNAs activities [12]. Kang et al. reported that HULC rs7763881 A/C polymorphisms could decrease the risk of esophageal cancer [13]. Cui and colleagues found that HULC was an oncogene in hepatoma cells. It could deregulate lipid metabolism [14]. Zhao et al. suggested that HULC was associated with lymph node and distant metastasis [4]. Xie et al. indicated that HULC could be a biomarker for the prognosis of hepatocellular carcinoma [15].

Some limitations should be addressed. First, another studies are needed to determine the results among different races. Second, publication bias cannot be ruled out. Third, we did not perform other subgroup analyses due to limited data.

In conclusion, this meta-analysis suggested that HULC was a biomarker of the prognosis of cancer.

\section{MATERIALS AND METHODS}

\section{Publication search}

A comprehensive online search was conducted on Online electronic databases (PubMed, EMBASE, and Wanfang database) from the earliest date to Aug 30, 2016. The words (or carcinoma) and (highly up-regulated in liver cancer or HULC) were searched, with no language or other restrictions. The whole text was reviewed if information in title or abstract is not sufficient to make a decision. Secondary searches of literature were conducted by searching the reference lists of the selected studies and relevant reviews to avoid missing.

\section{Inclusion and exclusion criteria}

Studies were included if they met the following criteria: [1] case-control or cohort study; [2] about the association between HULC and the survival of cancer; and [3] had available data or could be calculated from the paper. Accordingly, the exclusion criteria were [1] duplicate data, [2] reviews, abstracts, case report, or animal studies.

\section{Data extraction}

The following data were recorded from each article: first author, year, race, cancer type, numbers of patients, outcome, parameters used for adjustment, study design, study location, tumor stage, cutoff value, and analytical method. The data were extracted by two of the authors independently. Discrepancies between these two authors were resolved by discussion. The included studies were assessed independently by the two reviewers using the Newcastle-Ottawa Scale (NOS).

\section{Statistical analysis}

The strength of association between HULC and the survival of cancer was estimated by HR with corresponding 95\% CI. Q-statistic was applied to investigate heterogeneity among studies. P-value greater than 0.1 for $\mathrm{Q}$ test suggested a lack of statistically significant heterogeneity. The random-effect model (DerSimonian-Laird method) was used. In addition, the $\mathrm{I}^{2}$-test was employed to accurately measure the degree of 
heterogeneity. Furthermore, the $\mathrm{I}^{2}$-value less than $25 \%$ was equivalent to mild heterogeneity, and values between $25 \%$ and $50 \%$ was equivalent to moderate heterogeneity, whereas values greater than $50 \%$ was equivalent to large heterogeneity among studies. Potential publication bias was estimated by symmetry of funnel plot of HR versus the standard error of $\log (\mathrm{HR})$ and the visual symmetrical plot indicated that there was no publication bias among studies. Stratified analyses were conducted in terms of race and cancer type. All statistical tests in this meta-analysis were two-tailed and P-value $\leq 0.05$ was considered statistically significant unless otherwise noted. All statistical analyses were performed with Revman 5.1 software (Nordic Cochrane Center, Copenhagen, Denmark) and STATA 11.0 software (Stata Corporation, College Station, TX).

\section{CONFLICTS OF INTEREST}

The authors declare no conflicts of interest.

\section{REFERENCES}

1. Pharoah PD, Dunning AM, Ponder BA, Easton DF. Association studies for finding cancer-susceptibility genetic variants. Nat Rev Cancer. 2004; 4: 850-860.

2. Ponting CP, Oliver PL, Reik W. Evolution and functions of long noncoding RNAs. Cell. 2009; 136: 629-641.

3. Gupta RA, Shah N, Wang KC, Kim J, Horlings HM, Wong DJ, Tsai MC, Hung T, Argani P, Rinn JL, Wang Y, Brzoska P, Kong B, et al. Long non-coding RNA HOTAIR reprograms chromatin state to promote cancer metastasis. Nature. 2010; 464: 1071-1076.

4. Zhao Y, Guo Q, Chen J, Hu J, Wang S, Sun Y. Role of long non-coding RNA HULC in cell proliferation, apoptosis and tumor metastasis of gastric cancer: a clinical and in vitro investigation. Oncol Rep. 2014; 31: 358-364.

5. Li SP, Xu HX, Yu Y, He JD, Wang Z, Xu YJ, Wang CY, Zhang HM, Zhang RX, Zhang JJ, Yao Z, Shen ZY. LncRNA HULC enhances epithelial-mesenchymal transition to promote tumorigenesis and metastasis of hepatocellular carcinoma via the miR-200a-3p/ZEB1 signaling pathway. Oncotarget. 2016; 7: 42431-42446. doi: 10.18632/ oncotarget. 9883 .
6. Peng W, Gao W, Feng J. Long noncoding RNA HULC is a novel biomarker of poor prognosis in patients with pancreatic cancer. Med Oncol. 2014; 31: 346.

7. Jin C, Shi W, Wang F, Shen X, Qi J, Cong H, Yuan J, Shi L, Zhu B, Luo X, Zhang Y, Ju S. Long non-coding RNA HULC as a novel serum biomarker for diagnosis and prognosis prediction of gastric cancer. Oncotarget. 2016; 7; 51763-51722. doi: 10.18632/oncotarget.10107.

8. Peng W, Wu J, Feng J. Long noncoding RNA HULC predicts poor clinical outcome and represents pro-oncogenic activity in diffuse large B-cell lymphoma. Biomed Pharmacother. 2016; 79: 188-193.

9. Sun XH, Yang LB, Geng XL, Wang R, Zhang ZC. Increased expression of IncRNA HULC indicates a poor prognosis and promotes cell metastasis in osteosarcoma. Int J Clin Exp Pathol. 2015; 8: 2994-3000.

10. Uzan VR, Lengert A, Boldrini E, Penna V, ScapulatempoNeto C, Scrideli CA, Filho AP, Cavalcante CE, de Oliveira CZ, Lopes LF, Vidal DO. High expression of HULC is associated with poor prognosis in osteosarcoma patients. PLoS One. 2016; 11: e0156774.

11. Zhang YF, Song XJ, Wang XX, Hu JC, Jiang LX. Silencing of IncRNA HULC enhances chemotherapy induced apoptosis in human gastric cancer. J Med Biochem. 2016; 35: 137-143.

12. Wang J, Liu X, Wu H, Ni P, Gu Z, Qiao Y, Chen N, Sun F, Fan Q. CREB up-regulates long non-coding RNA, HULC expression through interaction with microRNA-372 in liver cancer. Nucleic Acids Res. 2010; 38: 5366-5383.

13. Kang M, Sang Y, Gu H, Zheng L, Wang L, Liu C, Shi Y, Shao A, Ding G, Chen S, Tang W, Yin J. Long noncoding RNAs POLR2E rs3787016 C/T and HULC rs7763881 $\mathrm{A} / \mathrm{C}$ polymorphisms are associated with decreased risk of esophageal cancer. Tumour Biol. 2015; 36: 6401-6408.

14. Cui M, Xiao Z, Wang Y, Zheng M, Song T, Cai X, Sun B, Ye L, Zhang X. Long noncoding RNA HULC modulates abnormal lipid metabolism in hepatoma cells through an miR-9-mediated RXRA signaling pathway. Cancer Res. 2015; 75: 846-857.

15. Xie H, Ma H, Zhou D. Plasma HULC as a promising novel biomarker for the detection of hepatocellular carcinoma. Biomed Res Int. 2013; 2013: 136106. 